\title{
Venezuela Nostálgica. Reelección, Ruptura y Revolución
}

\author{
Ángel Dámaso Luis León ${ }^{1}$ \\ Universidad de La Laguna
}

La República de Venezuela fue un oasis en América Latina, un país estable, democrático y próspero durante varios lustros hasta la llegada de la crisis de los años ochenta. El nuevo contexto y el desgaste experimentado por los actores tradicionales forzaron cambios políticos profundos. La crisis, los ajustes realizados durante los noventa y las esperanzas de la población de un día regresar a las senda del bienestar generaron respuestas políticas cada vez más radicales. En este artículo se busca analizar las respuestas que da el pueblo venezolano a los desafios que les presenta su nueva realidad socioeconómica y que entroncan con ciertas visiones derivadas de la experiencia pasada, así como de su forma de concebir el papel del Estado y el del líder. También estudia la frustración generada al no cumplirse las expectativas depositadas por los ciudadanos, llevando a la elección de opciones cada vez más radicales.

Palabras Clave: Venezuela; Revolución bolivariana; Hugo Chávez; Rafael Caldera; Carlos Andrés Pérez; sistemas de partidos.

Cómo Citar este artículo / Citation: Luis León, Ángel Dámaso, "Venezuela Nostálgica. Reelección, Ruptura y Revolución”, Revista de Indias, LXXVII/270 (Madrid, 2017): 431-461, doi:10.3989/revindias.2017.014.

\section{INTRODUCCIÓN Y ACERCAMIENTO A LA CUESTIÓN}

Mientras en Latinoamérica se imponían las llamadas Dictaduras del Cono Sur y los Pinochet, Stroessner o Videla se afanaban en gobernar con mano de hierro sus países, la República de Venezuela encadenaba varias décadas de crecimiento y democracia. Después de la caída del general Marcos Pérez Jiménez en 1958 y el regreso al sistema democrático y tras una convulsa primera mitad de siglo XX, las libertades políticas llegaron a un país que se

1 Ángel Dámaso Luis León, contratado predoctoral del Departamento de Geografía e Historia de la Universidad de La Laguna y doctorando del Programa Interuniversitario Islas Atlánticas. E-mail: aluisleo@ull.edu.com ORCID iD: http://orcid.org/0000-0003-1311-9679. 
consolidó a la cabeza de la estabilidad democrática dentro de la región, auspiciada por un sistema de partidos robusto.

Esta estabilidad pudo ser mantenida a largo plazo debido a la bonanza económica generada por los pingües ingresos petroleros que obtuvo el país en los años sesenta y, sobre todo, tras la crisis de 1973. La riqueza fácil generada por la extracción de los hidrocarburos permitió consolidar un modelo de país que se situaba a la vanguardia de la región, pero también posibilitó de manera indirecta que se produjeran «vicios» que generaron problemas en la siguiente década.

La consolidación de la democracia y del sistema de partidos generó una estable continuidad institucional en el país. Aún así, ello no quiere decir que no existieran elementos políticos y económicos que pusieran en tela de juicio dicha estabilidad, desde la actuación de los grupos violentos ligados a la izquierda radical en la década de los setenta ${ }^{2}$, hasta la creciente corrupción existente en todos los sectores de la sociedad y, principalmente, dentro del Estado.

El estallido de la crisis económica de los primeros años de la década de los ochenta solamente fue el pistoletazo a un proceso de depauperación socioeconómica que se trasladó al ciudadano de manera lenta pero constante. Ante la situación de deterioro y la imposibilidad por parte de los presidentes Herrera Campins y Jaime Lusinchi de encontrar soluciones, los venezolanos buscaron rescatar viejas formas de gobierno, con la esperanza de que éstas trajeran nuevamente las mieles del progreso.

La apuesta por la figura del líder-benefactor que repartiera las rentas petroleras entre el pueblo tras años de crisis se embarcó en tres proyectos diferentes. El primero fue una propuesta de reelección que mostraba las ansias de los venezolanos y el repudio hacia la crisis que vivían. El segundo vino de la mano de otro de los obradores del sistema de la petrorriqueza de los sesenta, aunque ello supusiera romper con uno de los sistemas de partidos más estables del mundo. Y, por último, se produjo el advenimiento de un outsider golpista con tintes mesiánicos que prometía devolver una supuesta democracia robada al pueblo.

En este artículo se analizarán las claves de los cambios institucionales en Venezuela y el peso de la economía en el proceso de selección de líderes en el país, pero sobre todo se diseccionará la forma en la que los venezolanos fueron abandonando poco a poco su sistema de partidos estable y fueron apoyando proyectos basados en el carisma de unos líderes que les hablaban de un pasado donde la realidad era más alegre y la situación más boyante.

2 Para ampliar: Alexander, 1971: 67 y ss. 
El proceso de derrumbamiento del sistema de partidos venezolano y el advenimiento de un personaje peculiar como Chávez ha sido un reclamo importante para la historia y otras ciencias sociales. El papel jugado durante los años siguientes por el líder bolivariano en el tablero regional ha hecho que su figura y los motivos por los que llega al poder hayan sido estudiados por autores de diversa procedencia.

Si bien ningún estudio ha analizado los tiempos del proceso de ruptura poniendo tanto énfasis en los momentos de cristalización de la ruptura como este estudio, sí que hay varios que buscan esclarecer de manera extensa el proceso de cambio experimentado por la Venezuela de finales del siglo XX. A nivel general se pueden destacar las obras del venezolano Manuel Caballero o de los europeos Rickard Lalander y Ángel Luis León ${ }^{3}$. Ya que todas ellas intentan, de manera sintética analizar un proceso de cambio tan amplio y con tantos matices.

Desde un punto de vista interno de análisis de la propia revolución bolivariana también hay notables publicaciones. Desde una perspectiva comparativa resulta interesante la obra de Kirk Hawkins, aunque también hay otras publicaciones puramente analíticas como la de la historiadora venezolana Margarita López Maya, o la obra del británico Richard Gott, interesante aunque con cierto sesgo hacia el discurso chavista ${ }^{4}$.

A nivel específico también hay excelentes trabajos dedicados a aspectos concretos. Para estudios que pongan el énfasis en aspectos económicos y sobre el rentismo petrolero destacar los de Manuel Hidalgo o el de Toro Hardy $^{5}$, sin obviar nunca las publicaciones de diversas instituciones. A nivel de desarrollo democrático-institucional se pueden destacar los escritos de Juan Carlos Rey, para política exterior los de Carlos Antonio Romero o María Teresa Romero y para estudios sobre el sistema de partidos se deben remarcar los trabajos de Michael Coppedge ${ }^{6}$.

Por último, para aspectos más personales de una figura tan pintoresca se pueden recomendar el libro de Cristina Marcano y Alberto Barrera o las conversaciones editadas por uno de sus mentores Heinz Dieterich ${ }^{7}$.

3 Tanto en esta nota como en las siguientes se mencionará la obra que se considera más completa o adaptada a lo mencionado en el texto, en este caso: Caballero, 2000. Lalander, 2004. Luis León, 2015.

${ }^{4}$ Hawkins, 2010. López Maya, 2008. Gott, 2006.

5 Hidalgo Trenado, 2007a. Toro Hardy, 1992.

6 Rey, 2014. Romero, 2006. Romero, 2009. Coppedge, 1997.

7 Marcano y Barrera, 2004. Dieterich, 2007. 
UN SISTEMA DE PARTIDOS ESTABLE

La inestabilidad sufrida por el país durante la década de los cuarenta y cincuenta, dictadura de Pérez Jiménez incluida, había marcado profundamente la personalidad política de los líderes que idearon el sistema de vuelta a la democracia que se estableció en el país entre los años 1958 y 1961. El sistema venezolano de partidos surgió en dos fechas clave que fueron las que aposentaron los cimientos de un sistema democrático estable y con un alto grado de apoyo ciudadano, una verdadera excepción dentro de la región latinoamericana ${ }^{8}$.

La democracia llegó a Venezuela tras un golpe cívico-militar producido el 23 de enero de 1958 y se consolidó a través de pacto intra-élites firmado el 31 de octubre de ese mismo año, más conocido como Pacto de Punto Fijo. En él los líderes de los tres partidos principales: el socialdemócrata Acción Democrática, el democristiano COPEI (Comité de Organización Política Electoral e Independiente) y el reformista Unión Republicana Democrática (URD) se comprometían a fortalecer el sistema institucional recién nacido a través de un gobierno de unidad nacional liderado por el más votado y con un programa mínimo común.

El segundo momento clave es la aprobación por parte del entonces Congreso de la República de la Constitución de Venezuela, ratificada con un amplio consenso en el que participaron no solo las tres fuerzas anteriores, sino también el Partido Comunista de Venezuela.

El sistema puntofijista generó a medio plazo un bipartidismo estable entre Acción Democrática (AD) y COPEI tras la temprana implosión de la URD en los sesenta. Los partidos aprovecharon el vacío social de una Venezuela que se modernizaba y lograron permear a toda la sociedad cooptando nuevas organizaciones y corrientes de opinión e intereses que se habían creado (sindicatos, grupos de campesinos, asociaciones docentes, estudiantiles o profesionales $)^{9}$, potenciando el desarrollo propio como canalizadores únicos de opinión.

8 Se afirma esto porque Venezuela es el único de los países latinoamericanos de considerable tamaño que ha mantenido un sistema democrático y con alto apoyo ciudadano por varias décadas. Si bien Colombia también posee un sistema democrático conseguido tras la caída de la Junta Militar que sucedió a Rojas Pinilla (1958), el grado de participación popular en las elecciones realizadas desde entonces muy rara vez ha superado el $50 \%$ del censo electoral. Véase: Comunicado de prensa $N^{\circ} 223$ de 2010. Anexo: Elecciones presidenciales 1958-2006, 16 de junio de 2010, Bogotá, Registraduría Nacional del Estado Civil (consultado el 04-082016).

9 Kulisheck, 1999: 74. 
Si bien el sistema garantizaba las libertades democráticas indispensables en cualquier estado de derecho y se mostraba cohesionado, también es cierto que dejaba pocos espacios para la apertura interna de los agentes importantes o dificultaba la participación fuera de los canales habituales. En definitiva, se puede decir que AD y COPEI fomentaron un sistema consensual, elitista y, hasta cierto punto, corporativo ${ }^{10}$.

\section{LA CRISIS DE LOS OCHENTA}

Venezuela entraba en la década de los ochenta en medio de una euforia económica sin contención. El precio del crudo se situaba en torno a los $35 \$$ / barril, multiplicando su precio casi por cuatro con respecto a enero del año $1979^{11}$ y propiciando que las mieles de la abundancia que habían cubierto el país desde hacía varios lustros siguieran por mucho tiempo.

El copeyano Luis Herrera Campins ocupaba el Palacio de Miraflores desde el año 1979 y desde su posición observaba como las ganancias por ingresos de petróleo se multiplicaban y llenaban las arcas del Estado. El problema se encontraba en que esos petrodólares salían de dichas arcas nada más entrar, debido al aumento de gasto del gobierno. El crecimiento del gasto público en los primeros cuatro años de Herrera Campins fue de un 77,3\% (1978-1982) ${ }^{12}$, haciendo que éste fuera inasumible solo con los ingresos estatales. La euforia existente hacía imposible un frenazo en el gasto por lo que el gobierno socialcristiano se apoyó entonces en la deuda pública que creció nada menos que un $71,8 \%$ entre los años de 1979 y $1983^{13}$. Todo ello mientras anunciaba que tenía «un sostenido propósito de ordenar y disciplinar el gasto público y el saneamiento de las finanzas» ${ }^{14}$.

Tras esa careta de austeridad, el gobierno de Herrera Campins se subió a un carrusel de gasto inasumible. La ya considerable renta petrolera no daba para saciar al mastodóntico Estado que estaba construyendo el gobierno, dentro de un país que se encontraba en expansión demográfica y cuya consolida-

10 Hidalgo Trenado, 2007b: 15.

11 Datos extraídos de la web de la U.S. Energy Information Administration, disponible en http://www.eia.gov/dnav/pet/hist/LeafHandler.ash $x ? n=$ pet $\& s=f 000000 \_3 \& f=m \quad$ (consultado el 29-07-2015).

12 Datos oficiales del Banco Central de Venezuela publicados a través de Antivero, 2002: 9 .

13 Contreras, 1989: 12.

14 "III mensaje anual ante el Congreso de la República", Luis Herrera Campins, El Nacional, Caracas, 11/03/1982 (consultado el 08-08-2016). 
ción fiscal no petrolera era prácticamente nula. El recurso de la deuda fue utilizado dentro de la idea generalizada de que el petróleo era un producto con demanda inelástica y que en el futuro se podría solventar con nuevos pagos ligados a la venta de más barriles. Craso error.

La primera sacudida llegó al país en forma de problemas financieros el llamado "viernes negro». El 18 de febrero de 1983 se produjo una fuerte devaluación de un, hasta ese momento, bastante estable bolívar ${ }^{15}$. Las medidas tomadas por el gobierno no fueron demasiado acertadas, se introdujeron restricciones a la creciente salida de divisas que se venía produciendo desde el año anterior y se creó el llamado RECADI (Régimen de Cambio Diferencial) que buscaba la implantación de un régimen de cambio monetario que frenara la sangría, pero que en realidad solo fue la fuente de una parte notable de la corrupción en el segundo lustro de los ochenta.

El bienio 1982-1983 fue nefasto para la economía financiera del país. La huida de divisas se generalizó y el PIB llegó a caer un 5,5\% en 1983. Varios años en los que se alternan la recesión con el crecimiento escaso son la prueba de que la economía venezolana no se encontraba bien y aunque en los años subsiguientes los indicadores macroeconómicos mejoraran, fue un espejismo.

Los venezolanos tomaron la salida más habitual cuando la crisis empezaba a azotar al país, castigar al partido de gobierno y darle el poder a la oposición. En este caso, Jaime Lusinchi (AD) se había aupado a la Presidencia con más de $56 \%$ del voto válido y auspiciado por el voto de castigo a COPEI.

El poco carismático Lusinchi no sería el hombre llamado a atajar los graves problemas. Nada más lejos de la realidad, se atrincheró en el optimismo petrolero y llegó a hacer declaraciones tan infortunadas como aquella famosa afirmación de que «la botija está llena» ${ }^{16}$ en alusión a las arcas del Estado.

La situación se agravó durante el resto de la década debido a la mala renegociación de la deuda externa hecha por el gobierno de Lusinchi. El sistema de control de cambio de divisas resultó ser ineficaz. La disponibilidad de moneda extranjera y la política de expansión del gobierno generaron falsas expectativas entre una población que comenzó a sentir los efectos de la devaluación y un aumento significativo de la inflación. A medida que la crisis se agudizó, Venezuela sufrió desequilibrios fiscales, aumentó del desempleo y del mercado informal de trabajo, se produjo una caída de la productividad y un crecimiento económico escaso. Mientras tanto, otros problemas empeo-

15 "Suspendida por dos días la venta de divisas", El Nacional, Caracas, 21/02/1983: 1 (consultado el 29-10-2015).

16 Felipe Ledezma, 1993: 197. 
raron, como la corrupción, la burocracia y la ineficiencia en la prestación de los servicios públicos básicos ${ }^{17}$.

Si bien el gobierno de Herrera Campins puede definirse como un gobierno superado por sus consecuencias, primero políticas y después económicas, el de Lusinchi puede ser identificado como uno de transición o de huida hacia delante. Su etapa de gobierno se basa en una continuación tímida del modelo que Venezuela llevaba adoptado desde hacía décadas de querer solucionar problemas grandes con pequeñas soluciones, pero no fue el artificiero que desactivara la bomba de relojería que era en ese momento la economía del país, sino que confió en que no le estallara en las manos e intentar pasársela al siguiente que la sentiría en todo su esplendor tras cinco años más de alimentación del problema ${ }^{18}$.

\section{EL RETORNO DEL REY SAUDÍ}

El gobierno de Lusinchi había finalizado mal. La población empezaba a sentir los estragos de la crisis y con las elecciones de 1988 cerca, los partidos principales se encontraban en medio de conflictos internos por ver quién encabezaría la candidatura a la presidencia. Eduardo Fernández se impuso al histórico Rafael Caldera en el seno de COPEI y Carlos Andrés Pérez venció a Octavio Lepage, el delfín del presidente Lusinchi.

A posteriori se demostraría que los adecos no se equivocaron al repescar a un hombre que guardaba la impoluta imagen de sus buenos años, mientras que los copeyanos habían errado al decantarse por un candidato nuevo en medio del descrédito que empezaba a sufrir la clase política. El día 4 de diciembre de 1988 Carlos Andrés Pérez ganaba las elecciones 52,9\% de los votos, contra el 40,4\% de su contrincante Fernández ${ }^{19}$.

La clave del proceso electoral era cómo AD había conseguido sobreponerse al gobierno de Lusinchi y vencer la habitual alternancia que había experimentado la presidencia de gobierno en Venezuela cuando el poder desgastaba a los adecos. Hasta ese entonces, AD se había convertido en el partido principal del país, ganando las elecciones legislativas incluso cuando perdía las

17 Hidalgo Trenado, 2007a: 4-5.

18 Luis León, 2015: 80.

19 "Elecciones presidenciales. Cuadro comparativo 1958-2000 (Voto Grande)", Centro Nacional Electoral, Caracas, Secretaría General, Dirección de estadísticas electorales, división de geografía nacional: 4 (consultado el 16-08-2015). 
presidenciales (1968 y 1978) $)^{20}$, pero siendo castigado en estas cuando el desgaste era palpable. En este caso, la temeraria huída hacia delante de Lusinchi a través de un proyecto de re-estatalización y endeudamiento había suavizado la crisis de época de Herrera y había granjeado unos niveles de apoyo ciudadano altos ${ }^{21}$, pero su actitud irresponsable dejaría al país al borde del colapso.

La victoria del presidente de la «Venezuela Saudita» fue posible debido a la buena imagen que traía consigo Pérez de su primer mandato. Carismático, hablador y melómano, CAP (como era conocido) y su partido centraron su campaña electoral en su figura ${ }^{22}$, dejando en un segundo plano las siglas del partido. Pérez poseía una personalidad arrolladora y un discurso que rozaba la demagogia ${ }^{23}$, regado de buenas dotes oratorias.

La realidad es que tanto Pérez como Fernández sabían del estado del país, pero bajaron bastante el nivel de la campaña presidencial, haciendo un uso mayor de los silencios que de las palabras. Durante la campaña de 1988, ninguno de los dos principales candidatos preparó al electorado para el shock económico que venía a la vuelta de la esquina. Fernández habló de reformas de mercado y prometió «cientos de miles de empleos bien remunerados» ${ }^{24}$, pero negó la posibilidad de que un acuerdo con el FMI fuera necesario. Mientras tanto, Pérez fomentó las expectativas con referencia continuas a «los buenos tiempos que se vivieron durante su anterior mandato» ${ }^{25}$. Pérez habló vagamente acerca de la necesidad de reformas económicas, pero su crítica discursiva enmascaró el contenido de las políticas que iba a adoptar. Aunque posteriormente admitiera en alguna entrevista que ocultó sus verdaderas intenciones para evitar el miedo en la población ${ }^{26}$.

20 "Comparativo: Diputados al Congreso electos, 1958-1998. Directos, Complementarios y Adicionales", Centro Nacional Electoral, Caracas, Secretaría General, Dirección de estadísticas electorales, división de geografía nacional: 4 (consultado el 16-08-2015).

21 Coppedge, 1997: 91-93.

22 Spots de la campaña presidencial de Carlos Andrés Pérez, 1988, disponible en https:// www.youtube.com/watch? $v=$ PwQrOiX5tk. y en https://www.youtube.com $/$ watch $? v=E J 3 G r-$ LWqHJk (consultados el 17-08-2015).

23 Autores como Elena Block defienden que Pérez fue uno de los presidentes que «utilizó estrategias y una retórica populista» en los noventa. Véase Block, 2015: 41.

24 "Eduardo está contigo", Spot electoral de Eduardo Fernández para las presidenciales de 1988, disponible en https://www.youtube.com/watch? $v=$ XnHuuy 4 C5QQ (consultado el 0808-2016).

25 "Carlos Andrés Pérez cierra su campaña con un multitudinario acto en Caracas", $A B C$, Sevilla, 04/12/1988: 46 (consultado el 08-08-2016).

26 Roberts, 2014: 217. 
Los venezolanos confiaron en el recuerdo de un presidente al que consideraban casi omnipotente, subestimando la escasa capacidad de maniobra que tendría en un contexto muy diferente. Pérez se sintió legitimado y no era para menos, había vencido con más de la mitad de los votos y AD había aguantado el varapalo quedándose a pocos escaños de la mayoría legislativa, por lo que no le sería difícil gobernar.

En 1988 la confianza en el bipartidismo seguía siendo fuerte, entre COPEI y AD mantenían al $81,6 \%$ de los diputados, pero ya comenzaba a vislumbrarse las sombras de la desafección a través de la abstención. En un país con una abstención tradicionalmente muy baja, se habían abstenido el $18,1 \%$ de los venezolanos llamados a las urnas. Un número bastante bajo de no ser porque la media hasta ese entonces era del 7,6\%.

Pérez llegó al poder con la convicción de que debía implementar una política restrictiva que sacara al país del endeudamiento y para ello se rodeó de un gobierno tecnocrático que fue conocido como los IESA Boys ${ }^{27}$. El Gran Viraje, así se denominó a la política implementada por el tachirense debido a la gran diferencia entre sus promesas y la política real que había adoptado.

Pérez se sentía lo suficientemente respaldado para implementarlo y creó un paquete económico basado en la austeridad y en el cual la influencia del FMI se dejaría notar ${ }^{28}$. Entre las principales medidas que Pérez adoptó estaban: liberar las tasas de interés, liberar el control de cambio y también los precios de varios productos de la cesta básica. También se implementaron incrementos tarifarios en servicios públicos (teléfono, agua, electricidad, gas), así como en los derivados del petróleo. Se produjeron recortes en los aranceles y congelación de cargos en la administración pública ${ }^{29}$, que generaron un clima de desencanto en la población.

Este paquete de medidas terminó con la paciencia de una población que sufría los estragos de la crisis. El 27 de febrero de 1989, en un ataque de rabia colectiva el pueblo de Guarenas y luego de Caracas (también de otras ciudades) se echó a la calle en una serie de protestas violentas que tardaron días en ser controladas por un gobierno que se excedió en la fuerza empleada. El Caracazo o Sacudón, como fue conocido, se llevó consigo millones de dólares en desperfectos, pero sobre todo se llevó la vida de varios centenares de venezolanos borrando la confianza que quedaba en CAP.

\footnotetext{
27 Para más información sobre los llamados "IESA Boys", véase: Coppedge, 1999: 35-36.

28 "El crecimiento ecológico y una solución al problema de la deuda se dan cita hoy en Davos", La Vanguardia, Barcelona, 04-02-1989: 9 (consultado el 21-08-2015).

29 Luis León, 2015: 84-85.
} 
El pueblo le había dicho a Pérez que le habían votado para lo que él había prometido: regresar a los años de la opulencia, pero ello era imposible. El presidente había sido cínico al negar la situación e ilusionar con algo que imposible. Al tachirense le había sobrado palabrería en la campaña y le faltó pedagogía tras la misma para explicar que un regreso a la abundancia era inviable.

Se venían cinco inestables años de presidencia y de una tímida recuperación a base de estabilizar las cifras del país por medio de un ajuste doloroso. La situación llevó a dos golpes de estado fallidos en 1992 (febrero y noviembre), de los cuales saldrían algunos de los líderes más importantes de la siguiente década, pero que en ese momento lo que dejaban entrever era el malestar existente.

El respaldo público a los intentos de golpe mostró definitivamente que el programa de reforma económica iniciado en 1989 carecía de apoyo y que la popularidad inicial del carismático Pérez, que alcanzaba el 70 por ciento a principios de 1989, había caído en casi cincuenta puntos ${ }^{30}$. Para empeorar la situación el propio presidente fue perdiendo el respaldo de su propio partido, el cual era su garante principal.

En una ambiente de corrupción acuciante y a la que se culpaba de los problemas, el presidente fue sorprendido en asuntos no del todo limpios y removido de su cargo a través de un impeachment ${ }^{31}$ apoyado por miembros de la oposición y de la propia $\mathrm{AD}$ tras una comisión de investigación. En mayo del1993, tras la remoción de Pérez, ocupó el puesto interinamente quien le había disputado la candidatura a la presidencia en las primarias adecas, el presidente del Congreso, Octavio Lepage ${ }^{32}$.

Sucedía así que Venezuela llegaba a una situación de interinato en la presidencia del gobierno, con un presidente que no había sido electo directamente en las urnas, un hecho que no se había producido desde la caída de Pérez Jiménez. Al corto interinato de Lepage le siguió la presidencia de Ramón José Velásquez, el cual accedió al poder con el apoyo de COPEI y AD y que gobernó acompañado de un gabinete prácticamente independiente través de una Ley Habilitante ${ }^{33}$. El corto gobierno de Velásquez no fue un gobierno de transición sensu estricto, pero se le pareció bastante. Su objetivo fue dar es-

30 Pérez Liñán, 2000: 69.

31 Lalander, 2009: 136-140.

32 "Venezuela Senate authorizes trial", New York Times, Nueva York, 22/05/1993, disponible en http://www.nytimes.com/1993/05/22/world/venezuela-senate-authorizes-trial.html (consultado el 21-08-2015).

33 Castillo de López, 2008: 127-134. 
tabilidad al país tomando decisiones a largo plazo, mantener el orden institucional y calmar las ansias que existían en el estamento castrense. A ello contribuyeron los partidos aceptando este interinato casi tecnocrático, ya que se centraron en las decisivas elecciones que tendrían lugar a finales del 93.

\section{LA IMPLOSIÓN DEL SISTEMA DE PARTIDOS}

Los partidos tradicionales en Venezuela habían sufrido un declive propiciado por el descontento popular ligado al empeoramiento económico. Gran parte de la población consideraba que los partidos no los representaban y ya en las elecciones de 1988 muchos electores habían optado por la abstención o por una tercera fuerza. Prueba de ello es que el izquierdista Movimiento Al Socialismo (MAS) casi había multiplicado por tres su resultado en las legislativas con respecto a los comicios anteriores.

Los grandes partidos no eran indiferentes ante este proceso de erosión de un sistema que duraba ya 40 años y que, sin duda, había tenido un papel importante a la hora de consolidar la democracia. Por ello trabajaron en un modelo de reforma del sistema electoral para el legislativo ${ }^{34}$ con la esperanza de que acabara con algunos de los vicios adquiridos durante tantas décadas de permanencia en el poder y la crisis de representatividad cesara. Esta efímera reforma fue poco productiva, la situación existente demandaba más urgentemente cambios dentro de las estructuras de los propios partidos que en el modelo de asignación de representantes.

Los interinatos de Lepage y Velásquez solo fueron un impasse de unos meses en la lucha partidista. Tanto COPEI como AD pensaron que el panorama se estabilizaría con tenues reformas y que tras situarse en un segundo plano y con una buena estrategia electoral para el año 1993, los electores volverían a confiar mayoritariamente en ellos, pero la realidad fue distinta.

El apoyo activo por parte de la ciudadanía a los partidos tradicionales estaba en decadencia. Esta decadencia se muestra en el porcentaje de individuos partidistas, que descendió entre los años 1973 y 1993 casi en 20 puntos. El porcentaje de aquellos que afirmaban tener un vínculo fuerte con un partido, entendido que dentro de este grupo se hallaban militantes y simpatizantes llegó a un 26,8\% en 1993. La hipótesis que mantiene González Fuentes es que hay un creciente número de electores independientes, y es este el electorado que al fluctuar de un partido a otro, genera cambios. Pero además,

34 Para un desarrollo de las discusiones mantenidas durante el proceso de aprobación, así como para conocer el sistema aprobado, véase: Nohlen, 2004: 410-413. 
las identidades partidarias son más débiles y, por tanto, más susceptibles de cometer una infidelidad respecto a su partido ${ }^{35}$. Con esta afinidad en decadencia no fue extraño que aparecieran nuevos actores con capacidad para competir por el voto.

Para entender el declive de la partidocracia venezolana se puede hacer referencia a dos tipos de condicionantes que acabaron con la misma: unos de corte exógeno y otros de tipo endógeno.

Exógenos a la estructura orgánica de los partidos o, cuanto menos colaterales a las mismas pueden mencionarse: la corrupción generalizada, la crisis económica, la represión excesiva utilizada para acallar las protestas ${ }^{36}$, las dos intentonas fallidas de golpe de estado y un desalentador panorama de empobrecimiento generalizado en el país que llegó a cifras alarmantes ${ }^{37}$.

Mientras que endógenos se deben considerar: el desgaste sufrido por parte de $\mathrm{AD}$ debido a la mala imagen del gobierno de Pérez, la división de la democracia cristiana y el surgimiento de nuevos partidos que canalizaron una parte del descontento.

El conjunto de dichos factores llegó a una situación de cambio relativamente profundo que cristalizó con los comicios presidenciales y legislativos de finales del 93.

\section{RETORNO Y RUPTURA}

El 5 de diciembre de 1993 se celebraron las elecciones presidenciales y legislativas que llevarían nuevamente al poder al yaracuyano Rafael Caldera. El ya por entonces septuagenario Caldera regresaba a la presidencia, 25 años después de abandonar el poder, pero el contexto que se iba a encontrar era bien diferente.

Más allá de la debacle económica, de la desafección popular y de la corrupción generalizada, las elecciones habían dejado un panorama político que poco tenía que ver con el que había lidiado Caldera en su anterior mandato. Comenzando por un legislativo partido en varios pedazos.

\footnotetext{
35 González Fuentes, 2003: 10-11.

36 "En emergencia personal de la morgue por elevado número de víctimas", Ultimas Noticias, Caracas, 01/03/1989: 10 (consultado el 30-10-2015).

37 Según el Banco Central de Venezuela, para el segundo semestre del año 1991 la pobreza general en el país se situaba en el $74,29 \%$, mientras que los datos de pobreza extrema llegaban hasta un 39,50\%. Véase: Silva y Schliesser, 1998: 27.
} 
Tabla 1. Elecciones venezolanas de 1993

\begin{tabular}{|l|c|l|c|}
\hline \multicolumn{2}{|c|}{ Legislativas } & \multicolumn{2}{c|}{ Presidenciales } \\
\hline Partido & $\%$ de Voto & Candidato & $\%$ de Voto \\
\hline Convergencia & $12,8 \%$ & Rafael Caldera & $30,5 \%$ \\
\hline MAS & $11,8 \%$ & & \\
\hline AD & $27,1 \%$ & Claudio Fermín & $23,6 \%$ \\
\hline COPEI & $26,1 \%$ & Oswaldo Alvarez Paz & $22,7 \%$ \\
\hline LCR & $19,7 \%$ & Andrés Velásquez & $22,0 \%$ \\
\hline
\end{tabular}

En los comicios del año 1993 al legislativo, nada menos que cinco fuerzas obtuvieron más de un $10 \%$ en porcentaje de votos, dejando marca de la fractura existente. Una verdadera anomalía para lo que venía siendo la norma dentro de este tipo de elecciones. La caída del «bipartidismo adeco-copeyano» no tenía precedentes, ni siquiera en las primeras elecciones con la URD «robando votos» a ambas formaciones los resultados en porcentaje para unas elecciones presidenciales habían sido tan bajos (46,3\% del total).

Estos resultados que confirmaron la ruptura del sistema de partidos venezolano y un fugaz sistema a cinco bandas fue posible por el desgaste y desmembramiento de los insiders y el crecimiento de partidos jóvenes que ocuparon gran parte del desencanto existente entre los votantes tradicionales de AD y COPEI, o que se aprovecharon de la abstención cercana al $40 \%$, que diluyó los porcentajes de voto de dichos partidos.

El caso de AD era hasta cierto punto esperado. Bien es cierto que era el partido más importante del país, pero sus dos últimos gobiernos habían sido nefastos y el último había tenido hasta el componente circense del juicio político a Pérez. Por ello no deja de ser llamativo que consiguieran una apretada victoria en el legislativo consiguiendo 55 diputados, 2 más que COPEI o hasta 15 más que La Causa $\mathrm{R}^{38}$ y hasta 16 senadores, con la misma distan-

38 Los resultados de las elecciones al Congreso en 1993 fueron: AD 55 diputados, COPEI 53, LCR 40, Convergencia 26, MAS 24, Otros 5. Datos extraídos de la web: Political Database of the Americas (1999), Venezuela, Diputados Electos en 1993, según Entidad Federal, Georgetown University and the Organization of American States, http:// pdba.georgetown.edu/ Elecdata/Venezuela/93diputados.html (consultado el 13-10-2015). 
cia sobre los democristianos ${ }^{39}$. A pesar de la caída, la implantación de AD en el país era notable y las redes clientelares no habían dejado de funcionar del todo. La idea que subyace de este resultado es que gran parte del electorado adeco no decidió posicionarse en otras opciones sino que simplemente se abstuvo. Lo limitado de esos trasvases de voto hizo que no se produjera un sorpasso legislativo y que AD siguiera siendo un partido capital.

Si bien es cierto que hubo un voto de castigo por su gestión de la crisis y por la creciente corrupción, esta concepción retrospectiva del voto, como premio o castigo al Gobierno por lo que ha hecho hasta el presente, no es sin embargo unánime. En las elecciones, al fin y al cabo, los votantes encargan a alguien que les gobierne durante los próximos años. Algunos estudios han concluido que el voto se rige por las expectativas acerca de cómo evolucionará la economía en el futuro ${ }^{40}$ y en el caso de $\mathrm{AD}$, la sorpresiva propuesta de austeridad de Pérez no ofrecía otra alternativa.

El elemento sorpresa se produjo sobre todo en el otro sector del sistema tradicional. La debacle de COPEI no puede entenderse sin conocer la división interna que se generó en el partido tras las derrotas de los años ochenta y por el ego del propio Rafael Caldera. Caldera se había presentado en 1983 y había sido claramente derrotado por Lusinchi, pero a pesar de ello se resistió a dejar el control del partido en manos más jóvenes. Logró colocar en la secretaría general del partido a su delfín, Eduardo Fernández pero, aún así, aspiraba a conseguir el apoyo para los comicios de 1988 pero perdió la nominación ante el propio Fernández ${ }^{41}$.

La inestabilidad del sistema existente y la efervescencia social motivaron que Caldera optara por una vía diferente de regreso a la presidencia. Desde su atalaya privilegiada de senador se embarcó en una tarea difícil de medrar en una ciudadanía desafecta para lo cual no dudó en utilizar la demagogia como arma, llegando incluso a justificar el golpe de estado fallido del 4 de febrero de $1992^{42}$. Caldera había perdido el control de la maquinaria de su partido y su nominación era poco probable pero su popularidad subió como

39 Los resultados de las elecciones al Senado en 1993 fueron: AD 16 senadores, COPEI 14, LCR 9, Convergencia 6, MAS 5. Datos extraídos de la web: Political Database of the Americas (1999), Venezuela, Senadores Electos en 1993, Georgetown University and the Organization of American States, http://pdba.georgetown.edu/Elecdata/Venezuela/ 93senadores.html (consultado el 13-10-2015).

40 Maravall, 2003: 74.

41 Crisp, Levine y Molina, 2010: 383.

42 Discurso de Rafael Caldera ante el legislativo tras el intento fallido de golpe de estado del 4 de febrero de 1992, disponible en https://www.youtube.com/watch? $v=O L T J y X Y L K 38$ y en: https://www.youtube.com/watch? $v=T u Z Q 1 N d b C 9 c$ (consultado el 14-10-2015). 
la espuma, por lo que se declaró como candidato independiente a unas presidenciales muy divididas, secundado por una «marca blanca» del COPEI: Convergencia ${ }^{43}$. Mientras tanto, en COPEI, Fernández se había quemado políticamente apoyando a un defenestrado Pérez con el objetivo de salvaguardar a toda costa la democracia y el puntofijismo. Como consecuencia, Oswaldo Álvarez Paz, gobernador del Zulia, pudo capitalizar el descontento y ganó las primarias del partido. Muchos partidarios naturales de Fernández salieron del partido y se sumaron a la candidatura independiente de Caldera. Álvarez Paz ganó fácilmente en unas primarias en las que participaron más personas que las que el COPEI decía tener como miembros. Con el partido fragmentado por la espantada de Caldera y con la maquinaria controlada por Fernández poco entusiasmada con el candidato presidencial, el COPEI estaba condenado a un resultado mediocre ${ }^{44}$.

El descrédito de los partidos tradicionales había sido recogido por formaciones con no demasiado tiempo de vida. Más allá de Convergencia, a la que habían llegado individuos desencantados de otros grupos, también aparecieron o se resituaron en posiciones de poder nuevas experiencias como el MAS o La Causa Radical (LCR).

El MAS no era un partido nuevo, ya existía y participaba de las instituciones desde los primeros años de los noventa. Nacido como una escisión del Partido Comunista (PCV) y situado a la izquierda de AD, fue un partido que sufrió variaciones constantes en sus cuadros. Tercer partido del país, siempre tuvo un papel testimonial a nivel nacional (10 congresistas de media) hasta que la abstención creciente desmovilizó a los votantes de otros partidos. A pesar del poco desarrollo nacional experimentado por el partido, su importancia a nivel regional fue siempre capital, convirtiéndose en un elemento crucial a la hora de entender la gobernabilidad en los estados venezolanos. Fue quizás la importancia de ese papel regional lo que lastró su potencial nacional debido a los conflictos internos que sufría ${ }^{45}$. A pesar de ello, en 1993 pudo sumar su nada desdeñable aportación para que Caldera pudiera ganar la nominación unido a los votos de Convergencia y de esa extraña coalición de partidos pequeños de todo signo que recibió el curioso nombre de «el chiripero». En definitiva, el acercamiento del MAS a Caldera fue crucial, pero también es inconcebible sin tres aspectos clave: la ruptura del ex presidente

43 "Declaración de Principios" y "Programa de Acción" de Convergencia, disponible en: http://americo.usal.es/oir/opal/Documentos/Venezuela/PartidoConvergencia/DeclaracionPpiosPC.pdf (consultado el 15-10-2015).

44 Crisp, Levine y Molina, 2010: 383-384.

45 Lalander, 2004: 182-183. 
con su antiguo partido y con el esquema bipartidista; la crítica desaforada a la política de Pérez y, por último, la promesa de excarcelación de los participantes en los intentos de golpe de estado de $1992^{46}$.

Pero quizás el fenómeno más llamativo de inicios de los noventa fue el ascenso de La Causa Radical (LCR). LCR no era un partido nuevo pero su visibilidad sí que lo era. Por varias décadas formó parte de la multitud de pequeños partidos situados en la izquierda venezolana. Su visibilidad empezó en los comicios de 1988, al obtener tres diputados. En las elecciones para gobernadores de 1989, su candidato Andrés Velázquez, un conocido sindicalista de Sidor ganó en el estado Bolívar, victoria que repetiría en unas elecciones de 1992 en las que además se verían reforzados en algunos municipios como la propia capital. Estas victorias le dieron un impulso a la organización y en las elecciones presidenciales de 1993 su candidato, el gobernador Velásquez fue considerado por analistas y encuestadoras como el principal obstáculo de Caldera hacia la victoria ${ }^{47}$. Finalmente y a pesar de las acusaciones de fraude $^{48}$, Velásquez solo pudo ser cuarto obteniendo el $22 \%$ de los sufragios. En esa carrera LCR venció con holgura al (MAS) y le arrebató tercer puesto en el sistema político, obteniendo una representación de 40 diputados y 9 senadores ${ }^{49}$. LCR era un partido netamente de izquierdas, sus simpatizantes en 1993 se situaban en el 1,6 en una escala izquierda-derecha-centro de 1 a $3^{50}$, lo cual puede parecer poco extremo pero es una cifra importante para un país donde el elector se solía autoubicar bastante a la derecha. LCR ganó territorio a la izquierda de un $\mathrm{AD}$ demasiado anquilosado y en decadencia $\mathrm{y}$, sobre todo a un MAS cuya división interna y apoyo a Caldera impidió que pudiera capitalizar el voto de los grupos rupturistas.

Los comicios dejaban unas instituciones divididas que poco tenían que ver con la tradición anterior. La difícil aritmética del legislativo llevó a concretar apoyos bastante pintorescos y a una multipolaridad desconocida hasta entonces. El sistema bipartidista se había roto sin remisión.

La victoria de Caldera, aunque no aplastante, sí que mostraba los deseos nostálgicos de una ciudadanía que quería regresar a una época pasada que sin duda había sido mejor. Venezuela se debatía entre dos almas, una vieja y una

46 Luis León, 2015: 134.

47 "Venezuela votes today, cautioned by Clinton", New York Times, Nueva York, 05/12/1993, disponible en http://www.nytimes.com/1993/12/05/world/venezuela-votes-todaycautioned-by-clinton.html (consultada: 16-10-2015).

48 Lalander, 2004: 178-179.

49 Para más información sobre La Causa Radical, véase López Maya, 1996: 139-144.

50 Molina et al., 2002: 493. 
nueva y en el medio Rafael Caldera, un hombre de la antigua política que había radicalizado su discurso y que se apoyó en su carisma político y en el recuerdo nostálgico de su gestión para regresar a una posición que siempre había ansiado. En cierta medida los motivos de la victoria de Caldera no se distanciaban mucho de la de Pérez ${ }^{51}$, pero en esta ocasión los venezolanos habían castigado a sus políticos haciendo saltar por los aires el sistema de partidos. Si bien entre la ruptura total y la continuidad la ciudadanía eligió la solución intermedia que presentaba Caldera, el ascenso de LCR fue sólo una muestra que vaticinaba lo que estaba por venir si la situación no mejoraba. La fractura total de la sociedad venezolana era ya latente y la aparición de nuevos actores desde fuera del sistema podía confirmar lo que dice el refrán: «a río revuelto, ganancia de pescadores».

\section{LOS INESTABLES AÑOS 90}

La victoria de Caldera se había producido bajo un paraguas idéntico que la anterior de Pérez, la promesa de que las cosas en el país irían a mejor, a pesar de que la realidad pareciese bien distinta.

Dicha inestabilidad era latente en todos los planos. En el plano político el propio Caldera debía jugar muy astutamente con un legislativo en el que en principio no sólo no tenía mayoría para dominarlo, sino que ni siquiera la suma de las fuerzas que le apoyaron durante la contienda electoral suponían el principal grupo en el legislativo. La suma de Convergencia, MAS y el conjunto inestable de pequeños partidos solamente igualaba a $\mathrm{AD}$ en la Cámara y quedaba en tercera posición en el Senado. A pesar la situación, Caldera no buscó un pacto fuerte con alguna de las otras tres fuerzas y su gabinete estuvo compuesto por personalidades salidas de Convergencia como Rubén Creixi, del MAS como Teodoro Petkoff o Pompeyo Márquez y un número importante de independientes ${ }^{52}$, en su mayoría de vocación democristiana.

Si bien Caldera no quiso articular grandes pactos que cimentaran su gobernabilidad en el legislativo y se decidió por defender los programas específicos, sí que hubo una especie de concordia con los partidos tradicionales. Las otras organizaciones políticas hicieron una discreta oposición, en el caso

51 Luis León, 2015: 133-134.

52 "Caldera presentó los nombres de su gabinete", El Tiempo, Bogotá, 01/02/1994, disponible en http://www.eltiempo.com/archivo/documento/MAM-30889 (consultado el 17-102015). 
de COPEI y AD suavizada porque el presidente no intentó quebrantar el «pacto institucional», según el cual ambos partidos se repartían las presidencias del Senado y de la Cámara ${ }^{53}$. Ello generó estabilidad para la aplicación de ciertas medidas, pero también frenó la posibilidad de reformar un sistema que se estaba anquilosando.

Los problemas políticos de Caldera no solo se restringen al ámbito más ordinario del día a día, ya que la extraordinaria situación del país conllevaba afrontar problemas no habituales. El más importante era la gestión de los militares sublevados en 1992. La gestión de este affaire por parte del presidente quizás no fue la más adecuada. Presionado por los deseos de un sector amplio de la ciudadanía, por las promesas dadas por algunos de los grupos que le apoyaron en la nominación $\mathrm{y}$, hasta cierto punto, guiado por mantener la coherencia con su discurso estrella del año 1992, el yaracuyano indultó a la mayoría de participantes en los dos golpes de estado. Si bien Caldera intentó ganar para sí el favor de algunos de los subversivos de 1992, infravaloró el calado de la decisión tomada, ya que no se emitió condena contra unos golpistas que se habían ganado el favor de una parte del pueblo, por lo que no quedaban inhabilitados para el servicio público ${ }^{54}$. Sin saberlo, Caldera había activado a un ciclón político sin precedentes en la historia de Venezuela: Hugo Chávez.

En el plano económico la situación era aun más tensa. Unido a la situación de debilidad que el país venía padeciendo desde los ochenta y a la crisis de deuda, se unió en 1994 una crisis bancaria. Esta crisis se materializó como una situación de insolvencia masiva en gran parte de la banca privada comercial como el Banco Consolidado o el Banco Latino, que acarreó la inyección de grandes aportes monetarios a dichas entidades, así como la posterior nacionalización de algunos de ellos. Caldera intentó paliar la crisis por medio de medidas de ajuste y programas que llevaban nombres rimbombantes como la Agenda Venezuela (el más importante) $)^{55}$ pero los resultados no fueron del todo satisfactorios ya que el país seguía en clara tendencia al empobrecimiento e incluso llegó a tener problemas puntuales de abastecimiento ${ }^{56}$.

Como resultado de las gestiones del gabinete Caldera y del entorno hostil que se encontró (endeudamiento, crisis bancaria, hundimiento de ganancias petroleras, etc.), al final del segundo período presidencial de Caldera se había producido un descenso del $9 \%$ en el ingreso per cápita con respecto al lustro

53 Sonntag, 1997: 19-20.

${ }^{54}$ Luis León, 2015: 119-122.

55 Ibidem: 148-155.

56 "Venezuela se quedó sin dolares para alimentos", El Tiempo, Caracas, 12/08/1994, disponible en http://www.eltiempo.com/archivo/documento/MAM-193398 (consultado el 20-10-2015). 
anterior, se había multiplicado casi por dos la tasa de desempleo llegando al 11,3\% (1998). Además, aumentó hasta doce puntos la economía informal desde el ya alto $38 \%$ de 1993 y la inflación se disparó siendo el peor año 1996, cuando los indicadores calcularon un incremento del 103,2\%57. En definitiva, la larga crisis que había comenzado a principios de los ochenta seguía cebándose especialmente con los venezolanos, el número de personas pobres en el país había sobrepasado ya los 13 millones para 1997, situándose la tasa de pobreza en el $54,5 \% 58$ y el consumo por hogar había crecido en trece años (1984-1997) sólo un 19,4\%, mientras que en otros países de la región como Argentina (74,5\%), Brasil (67,2\%), Colombia (55,6\%) o Uruguay $(89,7 \%)$ triplicaban y hasta cuadruplicaban dichos guarismos 59 .

A esta situación de inestabilidad política y económica se le unió el consiguiente malestar social. Durante el mandato de Caldera (1994-1998) dicho malestar se tradujo en una media de 198 protestas al año, de las cuales casi un $31 \%$ eran de carácter violento ${ }^{60}$. Además de ello, en el Latinobarómetro de 1997 para Venezuela un 62,5\% de los venezolanos se encontraba «No muy satisfecho» o «poco satisfecho» con la democracia, un 63\% tenía «poca» o «ninguna» confianza en el Presidente, y un 77,2\% tenían las mismas respuestas para los partidos políticos. Un 48,3\% de los encuestados definía la realidad del país como «nada estable» y un $29,4 \%$ le caracterizaban como «algo estable». El grado de desafección era tal que un 49,4\% de los venezolanos consideraban que el voto no tenía importancia para cambiar la situación futura ${ }^{61}$.

Con esta situación de inestabilidad política y desasosiego en el ciudadano transcurrió el mandato de Rafael Caldera en la presidencia, la cual abandonó en 1999, no sin antes recibir una reprobación del electorado en las elecciones regionales de 1995 y 1998 que fueron una verdadera debacle para la efímera y personalista Convergencia ${ }^{62}$. El año 98 llegaba y con él la renovación de

57 Hidalgo Trenado, 2007b: 18.

58 "Poverty \& Equality data: People living below national poverty line", World Bank, Venezuela, Bolivarian Republic of Venezuela, 1997-2012, disponible en http://databank.worldbank.org/data/views/reports/ReportWidgetCustom.aspx?Report_Name=Country_chart2_Ju$n e 04 \& I d=d f 2 c 4 c a 09 f \& t b=y \& d d=n \& p r=n \&$ export $=y \& x l b l=y \& y l b l=y \& l e g e n d=\quad y \& i$ spor tal $=y \&$ inf $=n \&$ exptypes $=$ Excel\& country $=V E N \& z m=n($ consultado el 22-10-2015).

59 Datos extraídos de la base de datos Penn World Table del Groningen and Development Centre (Universidad de Groningen, Paises Bajos) (consultado el 22-10-2015).

60 Datos extraídos de El Nacional, disponible en González Fuentes, 2003: 22-23.

61 Datos extraídos del Latinobarómetro, Sección Venezuela, para 1997 (consultado el 2210-2015).

62 Datos extraídos de "Cuadro comparativo. Gobernadores electos por entidad. Elecciones 1989-1992-1995-1998-2000”, Centro Nacional Electoral, Secretaría General, Dirección de estadísticas electorales, división de geografía nacional (consultado el 22-10-2015). 
las cámaras legislativas y del gobierno, pero esta vez estos comicios no serían unas elecciones más sino que darían pie a la llegada de uno de los mayores terremotos políticos de finales del siglo XX y principios del XXI en Latinoamérica.

LOS COMICIOS DE 1998

Las elecciones de noviembre y diciembre de 1998 serán los comicios que marcarán el principio del fin de un entramado institucional y de una forma de hacer política. Un nuevo actor, el chavismo, había llegado desde fuera del sistema no solo para quedarse, sino para intentar renovar las formas e instituciones de la democracia venezolana.

El 8 de noviembre los venezolanos fueron llamados a las urnas para unas elecciones regionales y legislativas que serían el preludio de las presidenciales del mes siguiente. Con unas regionales dominadas por los partidos tradicionales que ganaron la mayoría de los estados, las legislativas se desarrollaron como aparece en el siguiente cuadro.

TABla 2. Elecciones venEzolanas de 1998

\begin{tabular}{|c|c|c|c|c|}
\hline \multicolumn{3}{|c|}{ Legislativas (noviembre) } & \multicolumn{2}{|c|}{ Presidenciales (diciembre) } \\
\hline Partido & Senadores & Diputados & Candidato & $\%$ de voto \\
\hline MVR & 12 & 46 & \multirow[t]{6}{*}{ Hugo Chávez Frías } & \multirow[t]{6}{*}{$56,20 \%$} \\
\hline MAS & 5 & 17 & & \\
\hline PPT & 1 & 7 & & \\
\hline MEP & 0 & 1 & & \\
\hline PCV & 0 & 1 & & \\
\hline SI & 0 & 1 & & \\
\hline $\begin{array}{l}\text { PRVZL } \\
\end{array}$ & 4 & 20 & \multirow[t]{3}{*}{ Henrique Salas Romer } & \multirow[t]{3}{*}{$39,97 \%$} \\
\hline $\mathrm{AD}$ & 19 & 62 & & \\
\hline COPEI & 7 & 28 & & \\
\hline IRENE & 1 & 2 & Irene Sáez Conde & $2,82 \%$ \\
\hline Otros & 5 & 23 & Otros & $1,00 \%$ \\
\hline
\end{tabular}


En los resultados a diputados y senadores se evidencia la conformación de un sistema multipartidista en principio inestable. En primer lugar, se aprecia un mayor fraccionamiento del sistema de partidos. El «Número efectivo de partidos» aumenta de 3.4 en 1988 a 5.6 en1993, para situarse en 7.5 en esta elección. Indicativo esto de que un mayor número de partidos comparte las preferencias de los electores. El sistema bipartidista que dominó durante décadas pierde vigencia para dar paso a uno multipartidista ${ }^{63}$.

La victoria de $\mathrm{AD}$ en un efímero legislativo por el temprano llamamiento a una Asamblea Constituyente ${ }^{64}$, quedó ensombrecido por el ascenso de Proyecto Venezuela (PRVZL) y del Movimiento V República (MVR). La caída de Convergencia y de la dividida LCR, otrora novedades victoriosas, hablan de la volatilidad que había adquirido el sistema.

Si bien estas elecciones planteaban un escenario de lucha a dos para las generales, no se debe obviar que los porcentajes de voto para el Congreso Nacional reflejan la influencia de las elecciones de gobernadores. Estos comicios, lo cuales se produjeron sin demasiado split voting, sugieren que la mayoría de los electores tomó una decisión única para las tres votaciones (Asamblea regional, gobernador estatal y legislativo) ${ }^{65}$.

El valor de estos comicios legislativos fue, principalmente, de calentamiento para las generales. A las elecciones de diciembre se llegaba con dos proyectos políticos que representaban una antítesis. Por un lado estaba el candidato derechista Henrique Salas Romer de PRVZL y que había sumado el apoyo de los partidos tradicionales tras verse éstos sin posibilidades para aupar a un candidato competitivo. Si bien Salas Romer era identificado como el candidato de la continuidad, el discurso del por entonces gobernador del Estado Carabobo durante la campaña no se parecía en nada a la demagogia buenista de Pérez y Caldera, y no dudó en señalar su futura política de ajuste fiscal ${ }^{66}$. El hecho de encontrarse frente a frente con la radicalidad chavista y sin prácticamente competidores en su espacio electoral tras el temprano hundimiento de Irene Sáez, le permitió a Romer plantear una campaña sin paños calientes, pero su posicionamiento y origen no tardaron en despertar las dudas de hasta los sectores más moderados ${ }^{67}$. Hay que entender que si

63 Molina y Pérez Baralt, 1999: 36.

64 Rey, 2007: 309.

65 Molina y Pérez Baralt, 1999: 35-36.

66 "Paciencia para tener patria", El País, Madrid, 09/11/1998, disponible en http://elpais. com/diario/1998/11/09/internacional/910566009_850215.html (consultado el 23-10-2015).

67 "El socialdemócrata Claudio Fermín renuncia a la carrera por la presidencia", $A B C$, Madrid, 11/11/1998: 36 (consultado el 29-10-2015). 
bien $\mathrm{AD}$ y COPEI se sumaron al apoyo, éste no fue entusiasta, sino que se decantaron por el mal menor.

Por el otro lado, el ex golpista Hugo Chávez se presentaba por su partido: el MVR, pero junto a una nómina importante de pequeños (y no tan pequeños) grupos de izquierdas que le dieron su apoyo. Entre ellos destacaron el tradicional MAS, una importante escisión de LCR como fue Patria Para Todos, o el histórico PCV.

A pesar de que éstos no fueron los únicos candidatos, sí que fueron los que llegaron con posibilidades reales de victoria tras desinflarse la candidatura de la antigua Miss Universo Irene Sáez, que encabezaba un grupo de candidatos testimoniales.

Finalmente y como se puede observar en la tabla que aparece en la página anterior, Chávez consiguió la victoria con cierta facilidad, imponiéndose por más de dieciséis puntos a Salas Romer, aupado por los votos a su partido y por los del MAS. Su victoria fue total no sólo en términos absolutos, sino también territoriales ya que ganó en el $75 \%$ de los estados del país, solo perdiendo en seis (Amazonas, Apure, Delta Amacuro, Falcón, Nueva Esparta y Táchira) y venciendo incluso en el estado de procedencia de su contrincante por casi diez puntos de diferencia ${ }^{68}$.

A pesar de la minoría legislativa, el desencuentro entre las formas tradicionales de hacer política y la nueva de la que hablaba Chávez se había producido. Chávez no descansaría hasta llevar a cabo un programa maximalista que implicaba muchas veces saltarse las instituciones. Es paradójico como el país del consenso, el que llevaba 40 años de estabilidad partidista, eligió como presidente a un ex golpista que buscaba acabar con todo lo construido y reconstruirlo a su manera.

\section{EL CAMINO A ÍTACA}

La victoria de Chávez se produjo por la conjunción de una serie de elementos contextuales en Venezuela y una serie de habilidades y estrategias desarrolladas por el candidato. El discurso del de Sabaneta era ofensivo, pero operativo en una situación como la del país andino. El grado de operatividad discursiva y la importancia de la receta fue tal que no quedó como un pro-

68 Datos extraídos de "Elecciones 6 de diciembre de 1998. Presidente de la República. Votos válidos por entidad", Centro Nacional Electoral, Secretaría General, Dirección de estadísticas electorales, división de geografía nacional (consultado el 23-10-2015). 
yecto puramente venezolano, sino que se extrapoló a otras realidades como Bolivia, Ecuador ${ }^{69}$ e incluso España ${ }^{70}$.

Venezuela era un país fuertemente empobrecido y en crónica crisis económica. Los políticos tradicionales no solo no solucionaban los problemas en función de las expectativas ciudadanas, sino que además eran vistos como una parte del problema. El excesivo grado de atrofia de los elementos de cooptación de estos no permitía una oxigenación que posibilitara reidentificaciones con el electorado. En definitiva, la unión de la exclusión política con la económica generó un cóctel que fue aprovechado por un hombre con unas dotes notables para la persuasión.

Con esta situación, Chávez entra dentro del manual del perfecto populista que casi profetiza y reclama Laclau ${ }^{71}$, esa figura canalizadora de las ansias de los desplazados del sistema pero más allá de la teoría, su verborrea se pone en práctica de una manera calculada. Chávez encaja en el perfil del rupturista antipolítico que quiere devolver la grandeza a la patria, al pueblo, el que autores como Zanatta, Panizza o Hawkins han definido ${ }^{72}$. Es un outsider que llega desde fuera del sistema para limpiarlo, es grandilocuente, excesivo en sus discursos y se arroga la potestad de dignificar la patria de los que la han ensuciado. Caracterizando como el único con potestad para devolverle la democracia al pueblo y supone la representación de sus virtudes y de su «poder moral» ${ }^{73}$. Posee tendencia a culpar de los problemas a la dejadez del régimen anterior más que a las dificultades de la compleja realidad social lo que lleva a creer que con buena voluntad los problemas pueden resolverse ${ }^{74}$.

$\mathrm{Su}$ discurso es nacionalista a la par que «buenista», ya que se apropia de ciertos conceptos que tienen una serie de connotaciones positivas para el ciudadano como «Bolívar» o «pueblo». Los vacía de contenido y los utiliza en su favor, así como también se acerca a la religión como un medio de influencia popular. Su verbo es afilado contra sus adversarios a la par que indefinido, critica al sistema de partidos y ofrece una realidad nueva, pero inspirada en un pasado mítico, una verdadera democracia opuesta al «putrefacto» sistema anterior. Además de ello, era miembro de las Fuerzas Armadas

69 Shifter y Joyce: 2008.

70 Para un análisis de las relaciones hispanovenezolanas durante el chavismo, véase Luis León, 2016. Para el fenómeno Podemos, véase Torreblanca, 2015.

71 Laclau, 2005.

72 Zanatta, 2014: 17-22. Panizza, 2009: 9-49. Hawkins, 2010: 38-43.

73 "Soy guerrero por la patria", El País, Madrid, 06/12/1998, disponible en http://elpais. com/diario/1998/12/06/internacional/912898802_850215.html (consultado el 23-10-2015).

${ }^{74}$ Linz, 1999: 80. 
de Venezuela en un período en el que tenían muy buena imagen entre los venezolanos ${ }^{75}$.

Dentro de su indefinición programática no tiene reparos en afirmar que «no es socialista ni comunista» ${ }^{76}$ unos años después de dar un grandilocuente discurso en la Universidad de La Habana y recibir el apoyo explícito de Fidel Castro ${ }^{77}$. Cercano al castrismo pero también a personajes tan oscuros como el argentino Norberto Ceresole ${ }^{78}$, el Chávez de campaña se muestra camaleónico, modifica sus posicionamientos según quien sea el auditorio que le escucha, radicalizándolo frente a los que tienen ansias de cambio y modificándolo frente a los que lo pueden dejar atrás por radical ${ }^{79}$.

Esa es la culminación de su estrategia, que conlleva también una praxis política, la de la revolución bolivariana. En definitiva, Chávez lo que quería era una fórmula para volver a la bonanza redistribuidora a través de la mano de un Estado sobredimensionado y paternalista, justamente lo mismo que había prometido el primer Carlos Andrés Pérez. Con ello no se está hablando de asignación de recursos, no se afirma que la asignación de recursos de Chávez y los presidentes puntofijistas sea idéntica, pero sí que está bastante claro que la «solución Chávez» no era una solución de ruptura total como éste vendía. Una solución que volvía, por otros discursos a las mismas políticas que se habían desarrollado durante los años dorados de la IV República: el estatismo, el rentismo y el extractivismo.

En este caso se podrían tomar las palabras de Linz, quien propone que las crisis de regímenes democráticos son el resultado de la falta de efectividad o eficacia de gobiernos sucesivos al enfrentarse con problemas serios. Por ello, el derrumbamiento de dicho régimen, en este caso el sistema cuartorrepublicano, es el resultado de procesos iniciados por la incapacidad del gobierno de resolver problemas para los cuales las oposiciones desleales se ofrecen como solución ${ }^{80}$. En este caso un outsider como Chávez consigue acaparar el voto

75 A la pregunta: “¿Cuánta confianza tiene Ud. en... Fuerzas Armadas”. Mucha: 35,2\%; Algo: 27,5\%; Poca: 25,2\%; Nada 10,7\%; NS/NC: 1,5\%, datos extraídos del Latinobarómetro, Sección Venezuela, 1997 (consultado el 23-10-2015).

76 "Renegade Officer Favored in Venezuelan Election Today", New York Times, Nueva York, 06-12-1998, disponible en http://www.nytimes.com/1998/12/06/world/renegade-officerfavored-in-venezuelan-election-today.html (consultado el 23-10-2015).

77 "Discurso de Hugo Chávez en la Universidad de La Habana", Cuba, 14/12/1994, disponible en https://www.youtube.com/watch? $v=T E N E \_U T y N v k$ (consultado el 23-10-2015).

78 Malamud, 2009: 29-30.

79 "Jaime Bayly entrevista a Hugo Chávez", 1998, disponible en https://www.youtube. com $/$ watch? $v=m E 84 o 4 Y x h 70$ (consultado el 23-10-2015).

80 Linz, 1996: 93. 
del venezolano desencantado con la clase política de su país y llegar a la más alta magistratura del Estado. En este papel de auspiciador las masas no se debe obviar el lugar que ocupa el presidencialismo como forma de organización política tendente a la personalización ${ }^{81}$.

Chávez era un hombre que quería romper con las consecuencias que se habían ido gestando desde los ochenta en el país (pobreza, indigencia, centralización...), pero precisamente con una estrategia de gobierno similar, no a la que lo había producido en primera instancia que eran los últimos gobiernos de Pérez y Caldera, pero si a los que habían puesto el caldo de cultivo para que ello se produjera. Quizás Chávez ya tenía en mente generar un aumento de los ingresos por petróleo como hizo a partir de 1999-2000 e invertir ese dinero en mejorar la capacidad productiva (cosa que no fue así), pero resulta llamativo como en un país tremendamente endeudado como Venezuela, la respuesta al problema de mucho estatismo era añadirle más (que no mejor) Estado ${ }^{82}$.

\section{CONCLuSiones}

El estallido del sistema político tradicional venezolano durante los últimos años del siglo XX es inconcebible sin la crisis económica que asola el país desde inicios de la década de los ochenta. Si bien ésta no produce directa y unívocamente el colapso, sí que es la causante del principal elemento determinante para que ello se produzca: la exclusión social.

La democracia venezolana nace débil en los años cincuenta del siglo XX y consigue fortalecerse por dos hechos notables: un pacto intraélites que limita gran parte de la conflictividad inherente al disenso y, sobre todo, el apoyo ciudadano que recibe en las urnas. Este apoyo ciudadano casi unánime es posible principalmente por el carácter redistribuidor del Estado venezolano, que asocia democracia con redistribución.

Se tiende a creer que el apoyo a las libertades que la democracia conlleva se produce porque el electorado concibe dichas bondades, pero en realidad esto no siempre es así. Una parte del apoyo a las instituciones no está ligado directamente a los valores que representan sino a la capacidad que tienen estas para, directa o indirectamente, otorgar un cierto grado de bienestar a los ciudadanos $^{83}$. El caso de Venezuela encaja perfectamente en este perfil, mien-

\footnotetext{
81 Lijphart, 1997: 156.

82 Luis León, 2015: 204-205.

83 Rothstein, 2009.
} 
tras el Estado es capaz de otorgar ese grado de bienestar a los ciudadanos estos apoyan masivamente al mismo y a sus organismos e instituciones. Dicho de otra manera, no hay conciencia masiva de que la democracia sea un valor positivo per se, sino que se concibe que una democracia o, por lo menos, una buena democracia, solo puede recibir esa identificación si es capaz de conseguir que sus ciudadanos consigan vivir desahogadamente.

A medida que la crisis se agudiza y endurece, se van creando bolsas de excluidos en un sistema nacido en otra coyuntura. Dicha exclusión social (y su resonancia mediática), sufrida por algunos y observada por otros, es la que produce que un importante número de venezolanos retire su apoyo explícito al sistema.

Está claro que esa retirada de apoyo social no es repentina sino progresiva. El proceso de empobrecimiento en Venezuela dura casi dos décadas y el resquebrajamiento del sistema político tradicional no se produce de golpe, sino que se va derrumbando paulatinamente.

Decimos que Venezuela es un país nostálgico durante los últimos años del siglo XX porque intenta continuamente regresar a un pasado dorado imposible. Por ello, los primeros en sufrir el desgaste de ese proceso de desarticulación lento es su clase política. Entendiendo como clase política aquella que aparece dentro de los partidos tradicionales. El venezolano medio había entendido la redistribución como algo vital y los partidos tradicionales como los actores encargados de realizarla. El problema es que al sobrevenir la crisis el país comienza a perder eficacia y quienes son culpados de esos males son los nuevos «cogollos» partidistas, que son los primeros castigados en las elecciones de 1988.

En 1988, Venezuela decide que la mejor manera de regresar a la senda de la abundancia es a través del liderazgo casi mesiánico de Carlos Andrés Pérez y su camarilla de tecnócratas. Con la reelección de Pérez se castiga a unos líderes nuevos a los que se concibe como incapaces y corruptos, y se deja el país en manos de una figura de la época de «vacas gordas» creyendo que éste, con su varita mágica, podrá regresar al país al modelo de pan por votos.

La debacle que supone el segundo mandato de Pérez y el empeoramiento en las condiciones de vida de los venezolanos hacen que la afinidad con los partidos tradicionales descienda y que aparezcan nuevos grupos de poder en la escena política. La victoria de Caldera guarda relación con la elección anterior ya que se busca un líder fuerte, experimentado y con experiencia en gestionar la riqueza del país, con la esperanza de que, esta vez sí, el país pueda regresar a las mieles de la abundancia petrolera. Pero también muestra síntomas de ruptura con la ciudadanía: la división del voto que hace saltar al sistema de partidos tradicional, el apoyo a un líder que se desmarca de dichos 
partidos tradicionales y el ascensos de nuevas sensibilidades hacen que la elección y el mandato de Rafael Caldera supongan un paso más hacia un modelo en inminente ruptura.

Ese modelo de ruptura con las instituciones previas aparece en 1998 personalizado en la figura de Hugo Chávez. La cuesta abajo que sigue experimentando la economía y la desarticulación social existente hacen que la «solución» que observan los venezolanos a sus males sea radical. El apoyo masivo a una revolución tan negacionista como la bolivariana habla del grado de desconexión existente entre la clase política tradicional y el electorado. Llegado a estas fechas el ciudadano considera que poco tiene que perder y se lanza a los brazos del discurso incendiario de un ex golpista que culpa de todos los males existentes en el país a todo el entramado anterior y que promete borrar todas las huellas del mismo.

La realidad es que el tejido social venezolano se encuentra tan desestructurado en ese momento que adopta un remedio radical. Pero la revolución bolivariana emerge desde la confrontación, canaliza la rabia de un electorado que se encuentra desolado y halaga al pueblo y a la patria como fuente de toda virtud, eximiéndole de todas sus responsabilidades. El bolivarianismo define el puntofijismo como un mal en sí mismo y se liga a la herencia de los padres fundadores consiguiendo tres objetivos: 1) elevar el discurso nacionalista que defiende, 2) arrogarse el papel de restaurador del orden patrio y, por lo tanto, benefactor; y 3) eximir al pueblo de sus responsabilidades políticas y sociales. Un cóctel bien construido que consigue llevarle al poder en el año 1998.

En definitiva, las opciones políticas mayoritarias escogidas por los venezolanos para la última docena de años del siglo XX entroncan con un deseo latente en la sociedad del país. Hay un anhelo de regresar a las mieles del éxito, de que los bolívares permeen a todos los sectores de la población. Hay anhelo de volver a los que hicieron de Venezuela un país estable, próspero y deseado para miles de inmigrantes extranjeros y por ello se buscan soluciones que tengan como objetivo ese fin. Para conseguirlo, el elector no escatima en medios ni duda en poner sobre la mesa cada vez una apuesta más alta. En 1988 fue su clase política, en 1993 el viejo y estable sistema de partidos y, finalmente en 1998, el propio sistema institucional del país.

\section{BIBLIOGRAFÍA}

Alexander, Robert J., El Partido Comunista de Venezuela, México D.F., Editorial Diana, 1971. 
Antivero, Ignacio (comp. y coord.), Banco Central de Venezuela. Series Estadísticas de Venezuela. Cuentas Nacionales (Serie 1950-1998), Tomo I-A, Caracas, Banco Central de Venezuela, 2002.

Block, Elena, Political Communication and Leadership: Mimmetisation, Hugo Chávez and the construction of power and identity, Londres, Routledge, 2015.

Caballero, Manuel, La gestación de Hugo Chávez. 40 años de luces y sombras en la democracia venezolana, Madrid, Editorial Catarata, 2000.

Castillo de López, Haydee, "Las leyes habilitantes en la Constitución de 1961", VV. AA., Veinticinco años de pensamiento económico venezolano1983-2008, Caracas, Academia Nacional de Ciencias Económicas, 2008: 107-150.

Contreras, Hugo, "La deuda pública venezolana, 1979-1988", Revista Economía, IV (Mérida, 1989): 1-31.

Coppedge, Michael, Strong Parties and Lame Ducks: Presidential Partyarchy and Factionalism in Venezuela, Stanford, Stanford University Press, 1997.

Coppedge, Michael, Venezuela: Conservative representation without conservative parties, Notre Dame, Helen Kellogg Institute for International Studies, 1999.

Crisp, Brian F., Levine, Daniel H. y Molina, José E., "El ascenso y la decadencia del COPEI en Venezuela", Scott Mainwaring y Timothy R. Scully (eds.), La democracia cristiana en América Latina. Conflictos y competencia electoral, México D.F., FCE, 2010: 365-397.

Dieterich, Heinz (coord.), Hugo Chávez: El destino superior de los pueblos latinoamericanos y el gran salto hacia delante, Alcalá La Real, Alcalá Grupo Editorial, 2007.

Felipe Ledesma, Pedro, "Los últimos 30 años", Historia mínima de Venezuela, Caracas, Fundación de Trabajadores Lagoven, 1993: 185-202.

González Fuentes, Sonia, "Desconfianza política: El colapso del sistema de partidos en Venezuela" Documentos de trabajo (CSIC. Unidad de Políticas Comparadas), 14 (Madrid, 2003): 1-30.

Gott, Richard, Hugo Chávez y la revolución bolivariana, Tres Cantos, Ediciones Foca, 2006.

Hawkins, Kirk A., Venezuela's Chavismo and Populism in Comparative Perspective, Londres, Cambridge University Press, 2010.

Hidalgo Trenado, Manuel, A Petro-State: Oil, Politics and Democracy in Venezuela, Madrid, Working Paper49/2007 Real Instituto Elcano, 2007a.

Hidalgo Trenado, Manuel, "Venezuela: de la crisis del modelo de Punto Fijo al régimen Chavista", Revista Nuestra América, 4 (Oporto, agosto-diciembre 2007b): 13-35. 
Kulisheck, Michael, "Reformas del Congreso y representación política en Venezuela", América Latina, Hoy, 21 (Salamanca, abril 1999): 73-84.

Laclau, Ernesto, La razón populista, Buenos Aires, FCE, 2005.

Lalander, Rickard, Suicide of the Elephants? Venezuelan Decentralization Between Partyarchy and Chavismo, Helsinki, Renvall Institute Publications, University of Helsinki, 2004.

Lalander, Rickard, "The Impeachment of Carlos Andrés Pérez and the Collapse of Venezuelan Partyarchy", María Llanos y Levi Marsteintredet (eds.), Presidential Breakdowns in Latin América. Causes and Outcomes of Executive Instability in Developing Democracies, New York City, Palgrave McMillan, 2009: 129-146.

Lijphart, Arendt, "Presidencialismo y democracia mayoritaria", Juan José Linz y Arturo Valenzuela (comps.), La crisis del presidencialismo: Perspectivas comparadas, vol. 1, Madrid, Alianza, 1997.

Linz, Juan José, La quiebra de las democracias, Madrid, Alianza, 1996.

López Maya, Margarita, "Nuevas representaciones populares en Venezuela", Nueva Sociedad, 144 (Buenos Aires, julio-agosto 1996): 138-151.

López Maya, Margarita, "Venezuela: Hugo Chávez y el bolivarianismo", Revista Venezolana de Economía y Ciencias Sociales, III/15 (Caracas, septiembre-diciembre, 2008): 55-82.

Luis León, Ángel Dámaso, Chávez al poder. Génesis y formación del movimiento bolivariano, Santa Cruz de Tenerife, Ediciones Idea, 2015.

Luis León, Ángel Dámaso, “Las relaciones hispanovenezolanas durante el chavismo, 1998-2011”, Historia Actual Online, 40 (Cádiz, 2016): 45-58.

Malamud, Carlos, "Caracteres, rasgos y perspectivas de la «Revolución Bolivariana»" VV. AA., Venezuela y la Revolución Bolivariana, Madrid, Instituto Universitario Gutiérrez Mellado, 2009: 21-48.

Maravall, José María, El control de los políticos, Madrid, Taurus, 2003.

Marcano, Cristina y Barrera, Alberto, Hugo Chávez sin uniforme. Una historia personal, Caracas, Debate, 2004.

Molina, José Enrique, Hernández Márquez, Judith, Álvarez, Ángel E., López Maya, Margarita, Vaivads, Henry y Pereira Almao, Valeria, "Venezuela", Manuel Alcántara Sáez, y Flavia Freidenberg (eds.), Partidos Políticos de América Latina. Países Andinos, Salamanca, Universidad de Salamanca, 2002: 487-605.

Molina, José Enrique y Pérez Baralt, Carmen, "La democracia venezolana en una encrucijada: las elecciones nacionales y regionales de 1998”, América Latina, Hoy, 21 (Salamanca, abril 1999): 29-40.

Nohlen, Dieter, Sistemas electorales y partidos políticos, México D.F., FCE, 2004. 
Panizza, Francisco, El populismo como espejo de la democracia, Buenos Aires, FCE, 2009.

Pérez Liñán, Andrés, “¿Juicio político o golpe legislativo? Sobre las crisis constitucionales en los años noventa" América Latina, Hoy, 26 (Salamanca, diciembre 2000): 67-74.

Rey, Juan Carlos, "Sobre los conceptos de constitución y poder constituyente en el proyecto político de Hugo Chávez", SIC (Caracas, agosto 2007): 307-316.

Rey, Juan Carlos, "Los tres modelos venezolanos de democracia en el siglo XX", Mayoría o consenso en los modelos de 'democracia' en Venezuela durante el siglo XX, 2014, disponible en https://www.academia.edu/15453850/LOS_TRES MODELOS_VENEZOLANOS_DE_DEMOCRACIA_EN_EL_SIGLO_XX.

Roberts, Kenneth M., Changing Course in Latin America. Party Systems in the Neoliberal Area, New York, Cambridge University Press, 2014.

Romero, Carlos A., Jugando con el globo: la política exterior de Hugo Chávez, Barcelona, Ediciones B, 2006.

Romero, María Teresa, Política exterior venezolana: el proyecto democrático, 19591999, Caracas, Los libros de El Nacional, 2009.

Rothstein, Bo, "Creating Political Legitimacy: Electoral Democracy Versus Quality of Government", American Behavioral Scientist, 53/3 (California, noviembre 2009): 311-330.

Shifter, Michel y Joyce, Daniel, "Bolivia, Ecuador y Venezuela, la refundación andina", Política Exterior, XXII/123 (Madrid, 2008): 55-66.

Silva, José Ignacio y Schliesser, Renier, La evolución de la pobreza en Venezuela, Caracas, Banco Central de Venezuela, 1998. Serie Documentos de Trabajo, Gerencia de Investigaciones Económicas, 14.

Sonntag, Heinz R., "Venezuela. El difícil curso de la transición", Nueva Sociedad, 151 (Buenos Aires, septiembre-octubre 1997): 17-26.

Toro Hardy, José, Venezuela: 55 años de política económica, 1936-1991, Caracas, Editorial Panapo, 1992.

Torreblanca, José Ignacio, Asaltar los cielos: Podemos o la política después de la crisis, Madrid, Debate, 2015.

Zanatta, Loris, El populismo, Madrid, Katz, 2014.

Fecha de recepción: 16 de febrero de 2016.

Fecha de envío de las modificaciones: 5 de septiembre de 2016.

Fecha de aceptación: 9 de marzo de 2017. 


\section{Nostalgic Venezuela. Reelection, rupture and revolution}

The Republic of Venezuela was an oasis in Latin America, a stable, democratic and prosperous country for several decades until the coming of the 1980s' crisis. The new context and the erosion of traditional actors forced profound political changes. The crisis, the adjustments made during the 1990s and the population's hopes of one day returning to the path of prosperity generated increasingly radical policy responses. This article seeks to analyse the political responses of the Venezuelan people to the challenges posed by their new socioeconomic reality and how these connect with visions derived from past experience and the approach to the roles of state and leader. It also explores the frustration caused by failure to meet their expectations, leading to the election of increasingly radical options.

Key words: Venezuela; Bolivarian Revolution; Hugo Chávez; Carlos Andrés Pérez; Rafael Caldera; party systems. 